Universidade do Estado do Rio de Janeiro, Programa de Pós-Graduação em Ciências Sociais (UERJ-PPGCS), Brasil

II Universidade Federal do Rio de Janeiro, Programa de Pós-Graduação em Sociologia e Antropologia (UFRJ-PPGSA), Brasil octavio.bonet@gmail.com

III Universidade Federal do Rio de Janeiro, Programa de Pós-Graduação em Antropologia Social (UFRJ-PPGAS), Brasil otaviovelho@terra.com.br

\title{
A ANTROPOLOGIA COMO PARTICIPANTE DE UMA GRANDE CONVERSA PARA MOLDAR O MUNDO. ENTREVISTA COM TIM INGOLD
}

A ideia de fazer um dossiê sobre Tim Ingold surgiu de três constatações: primeiro, a repercussão que o autor vem ganhando no Brasil e na América Latina; segundo, a instigante entrevista realizada com Ingold e publicada neste número de Sociologia \& Antropologia; e, terceiro, as possibilidades teóricas e metodológicas que suscitam suas ideias.

Em 20I2, Tim Ingold voltou à América Latina para uma nova visita ao Brasil e aos países do MERCOSUL. Na oportunidade, proferiu a conferência de abertura do Seminário "O Trabalho da imaginação na textura do presente. Reflexões antropológicas a partir de etnografias desenvolvidas em Angola e Moçambique". Nessa palestra voltou a relacionar, como já o fizera em outros trabalhos, a antropologia com a imaginação, o ambiente e a vida.

Desde o seu primeiro trabalho etnográfico, de 1976, sobre os Skolt Saami do Nordeste da Finlândia, Ingold vem pensando sobre os modos como habitamos o mundo e sobre as habilidades [skills] específicas que geramos em relação a esse ambiente, e que nos permite habitá-lo. O habitar remeteria ao processo de desenvolvimento que necessariamente precisa da criatividade e da imaginação.

Essas ideias se desenvolvem ao longo de uma obra prolífica, cujo fio condutor é a busca por superar as oposições clássicas entre natureza e cultura, ou entre individuo e ambiente. Sua busca levou, consequentemente, à afirmação, em um dos seus últimos trabalhos, Being alive (2012), de que era "somente 
[just] um antropólogo", rejeitando os qualificativos de social, biológico ou arqueólogo. Nessa afirmação estaria intrínseca uma definição de antropologia, que buscaria devolver à disciplina o seu potencial para pensar a vida humana, e teria, ainda, uma proposta metodológica sobre o modo de realizar o trabalho antropológico, que Ingold denominou "conhecer de dentro", em Making (2013).

A linha que segue a obra de Tim Ingold tem uma forte correlação com sua trajetória profissional; inicialmente voltado para as ciências naturais, quando mudou para a antropologia não deixou de se interessar pelas relações entre os animais, os humanos e as coisas no entorno-ambiente. A partir daí, desenvolve a perspectiva ecológico-relacional que se configura ao longo dos seus trabalhos. Ingold lecionou inicialmente na Universidade de Helsinki; posteriormente, na Universidade de Manchester, até I999, quando foi para a Universidade de Aberdeen, onde fundou, em 2002, o Departamento de Antropologia e no qual ensina até hoje.

Quando esta entrevista foi realizada, em novembro de 20I2, contávamos com a participação da colega e amiga Clara Mafra, que veio a falecer em julho de 2013. Agora, por ocasião das revisões e da edição da entrevista, e no encaminhamento final para publicação, continuamos sentindo a sua presença conosco. Clara era uma discípula entusiasmada de Tim Ingold, com quem fez pós-doutorado em Aberdeen. Desde então adquiriu uma desenvoltura para lidar com esse conjunto de ideias, que chamamos de "a perspectiva de Ingold", habilidade - para usar uma dessas poderosas ideias - que ela foi ampliando cada vez mais, tendo, inclusive, participado da coletânea Creativity and cultural improvisation (organizada por Tim Ingold e Elizabeth Hallam em 2007) com o artigo "Um mundo sem antropologia" (traduzido em Antropolítica, 22, 2007). Assim é que planejou e organizou, em 2012, o seminário "O trabalho da imaginação na textura do presente", que teve como referência essa perspectiva de Ingold, cuja própria presença se destacou na palestra de abertura do evento. Desse modo, podemos também dizer que Clara foi a mentora da entrevista que agora publicamos, feita naquela ocasião. Queremos deixar isto aqui reconhecido, junto com nosso agradecimento e nossa homenagem a Clara Mafra, uma colega muito querida e respeitada.

Otávio Velho. Nos últimos anos você esteve aqui, na América Latina, algumas vezes. Eu gostaria de saber um pouco das suas impressões gerais, como foi sua experiência aqui, como você percebe o continente?

Tim Ingold. Na verdade, é a segunda vez; tecnicamente, é a terceira. Muitos anos atrás eu estive em uma conferência latino-americana de antropologia, em Caxambu, mas foi algo bastante pontual e breve, fui para a conferência e voltei. Já no ano passado eu estive em Brasília, em Belo Horizonte, Porto Alegre, Maldonado e Montevidéu. Este ano estive em Buenos Aires, Montevidéu novamente, Córdoba, Santiago, e agora estou aqui no Rio de Janeiro. 
Cada país é diferente e, do ponto de vista antropológico, ou em termos do que a antropologia representa e de como a antropologia é na América do Sul, cada contexto parece ser bem particular.

Aqui no Brasil, sem dúvida, a antropologia é uma disciplina muito forte e bem representada, perfeitamente capaz de caminhar sozinha, tem certa autonomia. Na Europa e no Reino Unido, pesquisadores que não são necessariamente especialistas em América do Sul conhecem muitos antropólogos e pesquisadores brasileiros. Provavelmente também conhecem pessoas do México, mas não conhecem muitos antropólogos de outros países da América Latina. A antropologia é, certamente, mais forte no Brasil do que em qualquer dos outros países do Cone Sul.

É engraçado, quando estive na Argentina as pessoas diziam que o Uruguai era um país bastante triste, que pouca coisa acontecia por lá. Depois eu estive no Uruguai e as pessoas se queixaram dos argentinos ricos, diziam que eles estavam "comprando o país inteiro". Depois, no Chile, as pessoas diziam que gostavam do Uruguai, talvez porque não gostam muito dos argentinos... É curioso perceber essas rivalidades que existem no continente.

Minha mulher e eu gostamos muito de Montevidéu. As pessoas dizem que é uma cidade meio adormecida, mas há uma geração mais jovem, que foi basicamente treinada no Reino Unido, na Europa ou nos Estados Unidos, que parece se sentir um pouco frustrada. Parece-me que eles gostariam de trazer novidades e dar impulso ao departamento [Departamento de Antropologia Social da Universidad de la República - Uruguai], e encontram problemas, por conta, talvez, do caos institucional, ou por alguma escassez de recursos, embora eu não creia que este seja um problema central. Tive essa impressão especificamente no Uruguai.

Quando fui a Buenos Aires, visitei a Universidade de San Martín e gostei muito de lá. É uma universidade nova, com um departamento novo de Antropologia, com pessoas muito entusiasmadas, que pensam em como construir alguma coisa nova. Eles se sentem de forma semelhante à como eu me sentia quando estava criando o departamento de Antropologia em Aberdeen, um momento de entusiasmo, de grande ímpeto, uma coisa muito boa.

A outra coisa que eles deixaram muito claro para mim é que na Argentina a antropologia está diretamente vinculada à política do país. A Argentina é tão guiada por conflitos, é uma sociedade tão tumultuada nesse sentido, que para ser um antropólogo parece que é preciso estar engajado na política local, e que não é possível ficar distante disso. É algo que ficou muito claro para mim quando estive por lá. Eles diziam que quando se faz antropologia na Argentina tem que ser de forma política, de forma engajada, e era por isso que, diziam eles, gostavam da Escola de Manchester, porque essa Escola trata da questão do conflito, e a antropologia recente não faz tanto isso. Eu acho que eles estão procurando mesmo suas características próprias. Mas na Eu- 
ropa, e no Reino Unido especificamente, ninguém sabe que existe alguma antropologia na Argentina, ou seja, ela não fez uma marca fora de seu país.

Depois eu fui a Córdoba. Lá as coisas são um pouco diferentes. Eles têm uma abordagem de três campos, juntando antropologia, arqueologia e antropologia física, acho que é o único lugar que faz essa mistura, é um programa bastante novo. Fui lá para dar uma palestra para doutorandos de várias cidades da Argentina, e do Chile também - eram sessenta estudantes muito bons, muito motivados, muito ativos e, eu diria também, sofisticados -, e nessa ocasião pensei que talvez fosse ali que as coisas cresceriam.

Em seguida fui a Santiago e, comparando o Chile com a Argentina, duas coisas me surpreenderam de forma significativa: a primeira é o quanto a era Pinochet lançou sombras sobre o pensamento no Chile. Passaram-se já uns dez anos desde o fim dessa era, mas as pessoas sempre enfatizam a questão da memória, do trato com o passado. Todos os chilenos que conhecemos, incluindo as pessoas que representavam as populações indígenas locais, eram seus porta-vozes, diziam que se sentiam muito vinculadas ao Chile, essa era sua primeira identidade; eram, pois, chilenos, sentiam-se profundamente identificados com a nação. Talvez por isso a era Pinochet tenha sido tão difícil para o Chile; se não se acredita em nacionalismos de qualquer ordem, um regime fascista não se justifica, pois se conclui que o regime fascista é ruim porque o nacionalismo é ruim. Porém, se a pessoa se sente extremamente vinculada à sua identidade nacional, e lhe sobrevém um regime que violenta isso, parece ser mais difícil para essas pessoas lidar com as consequências. Esse é só um dos aspectos. Os generais tomaram conta da Universidade, e parece que eles ainda precisam conviver com todos os estragos feitos durante esse período.

Outra coisa que me impressionou bastante é que, em comparação com a Argentina, o Chile é um país, de alguma forma, mais britânico, as pessoas são mais reservadas, não há lá aquela mesma exuberância que se percebe na Argentina.

Talvez eu esteja completamente equivocado, são apenas minhas percepções, mas essas foram mesmo as impressões que eu tive em minhas viagens por aqui.

O.V. Eu não sei até que ponto você sabe que muitos dos antropólogos que receberam você aqui na América Latina têm como tema central de estudo a religião - por exemplo, a Clara Mafra, o Carlos Steil, ou o Rolando Silla. Coincidentemente, eles foram meus alunos. A religião não aparece muito e explicitamente naquilo que você escreve, mas, ao mesmo tempo, algumas de suas críticas da Modernidade, ou do Ocidente, parecem ter alguma afinidade com o que pode ser lido em textos religiosos ou em textos místicos. Eu queria saber um pouco sobre a sua relação com este tema. 
T.I. Eu nunca tive um interesse particular, ou simplesmente não trabalhei diretamente, com a antropologia da religião, ou com o ritual. Não fui exatamente nessa direção porque trabalhei mais com a ecologia, com a relação entre humanos e animais. É por isso que o ritual e a religião não aparecem de forma proeminente ou explícita nos meus trabalhos. Mas é verdade também que, em algumas coisas que estive escrevendo recentemente, eu estou olhando, sim, diretamente para questões de religião, ou para o que é religião, a relação entre a ciência e a religião. Percebo que não posso evitar essas questões; em parte porque encontro muita inspiração em alguns dos filósofos medievais, ou dos antigos filósofos cristãos.

Estive revisando o trabalho sobre dragões que apresentei em outubro de 2012 e ao fazer isso pensei novamente sobre questões que têm a ver com o comprometimento ontológico, ou seja, sobre o que significa ver o processo de conhecer como uma parte do processo de ser. Assim como o mundo deve alguma coisa a nós por sua existência, também nós devemos alguma coisa ao mundo por nossa existência. Nesse sentido, quando se fala em coletar dados ou materiais, não se trata tão somente de coletar uma informação que está lá para ser colhida, mas sim de receber um tipo de oferta. E comecei a pensar que, afinal, é disto que a religião trata.

Acidentalmente, eu estava lendo O contrato natural, de Michel Serres, em que ele mostra que a derivação etimológica do termo religião é do latim relegere, ou seja, ler novamente, ler no sentido medieval, isto é, ser aconselhado pelo mundo, tomar conselhos do mundo, e daquilo que as pessoas dizem. Então, o contrário da religião não é o ateísmo, não é a falta de crença, e, sim, a negligência, negligere, não prestar atenção ao mundo, não ser aconselhado pelo mundo, não estar preparado para aprender com as coisas que estão à nossa volta. E daí pensei que é exatamente isso, religião é mesmo uma questão de comprometimento ontológico.

Estive conversando depois com alguns colegas no nosso departamento em Aberdeen, e também com pessoas do departamento de Teologia, e nós estamos chegando todos à conclusão de que precisamos de um novo tipo de relação entre a antropologia e a religião, na qual possamos levar a sério alguns dos insights da teologia prática, para que não seja uma antropologia da religião, mas uma antropologia com religião. Sentimos que as pessoas na teologia vêm dizendo esse mesmo tipo de coisa, enquanto a antropologia vem relativizando isto, referindo-se a religião, crença religiosa, ou outro sistema. De minha parte, me vejo tendendo para essa direção pela qual se pode realmente produzir uma abordagem simétrica entre antropologia e teologia, e acho que essa é uma perspectiva muito promissora.

Suponho que essa coincidência à qual você se referia em sua pergunta é porque há essa vertente em meu trabalho, sim, e só agora estou percebendo, e tentando resolver... ou seja, o que significa aprender com o que há dentro do 
ser [to know from the inside of being]. Por isto os tipos de questão com os quais venho lidando na relação entre a antropologia e a arte são muito similares àqueles que surgem a propósito das relações entre antropologia e religião.

Clara Mafra: Em sua defesa de uma antropologia baseada na obviação, a ênfase parece estar no fluxo da vida e sua múltipla constituição, na sensitividade contextual e na contingência. A ênfase nos fluxos da vida é certamente muito pertinente para enfrentar dicotomias disciplinares; contudo, parece que nos leva a um tipo de antropologia incapaz de capturar os determinantes das escolhas coletivas e individuais. Ao se colocar o foco na ontologia, não se estaria distanciando a antropologia daquilo que diz respeito às pessoas em suas vidas prosaicas?

T.I. Venho desenvolvendo uma abordagem que chamei de obviação [obviation] para tentar desmontar as distinções entre a antropologia social, a psicologia, a biologia, e assim por diante, mas há um problema nisso, que você está identificando aí. Ou seja, essa ênfase no fluxo da vida, nas continuidades, no crescimento, no desenvolvimento, às vezes parece estar descompassada com a realidade das vidas cotidianas das pessoas, particularmente porque essas vidas, de fato, são geralmente caracterizadas por rupturas, por deslocamentos, por aquilo que é o contrário mesmo do fluxo e da continuidade. Essa crítica foi feita várias vezes, acho que é válida, e um corolário dessa crítica tem a ver com o aspecto político, como eu abordo aspectos políticos em minha pesquisa... As pessoas estão de fato muito ligadas às questões políticas e de poder, mas isso parece marginal para a abordagem antropológica que estou tentando desenvolver.

Uma resposta a isso está em dizer que não se podem construir vidas a partir de rupturas e fraturas, da fragmentação, e que, de algum modo, a continuidade e o fluxo têm que vir antes da descontinuidade e da ruptura. Em outras palavras, uma coisa vem antes da outra. Para que possa haver a quebra, o conflito, a ruptura, o deslocamento, é preciso, primeiro, haver essas coisas para quebrar, é preciso haver a continuidade, o lugar, o movimento, o fluxo. É possível fazer uma barragem num rio, mas não se pode construir um rio de barragens.

Nesse sentido, eu acho que as continuidades da vida precisam vir antes. O que a maioria das pessoas faz em suas vidas é encontrar caminhos, brechas para passar. Temos todas essas rupturas, e barreiras, e as pessoas estão procurando brechas, passagens, vãos, para poder continuar, para permanecer. Eu acho que a coisa mais importante para as pessoas, em suas vidas, é simplesmente seguir, continuar, e assim para com seus filhos, e para com os filhos de seus filhos. As pessoas estão procurando fendas, brechas, uma forma de ultrapassar essas barreiras. E acho que, de algum modo, esses êxitos em encontrar caminhos devem vir antes, então, da ruptura e da fragmentação. Às vezes eu fico incomodado com essas tendências pós-modernas que dizem que 
tudo é ruptura, fragmentação. Acho que de alguma forma as pessoas estão vivendo e não se pode construir uma vida com esses fundamentos. Este é, portanto, um dos aspectos da questão.

Um segundo aspecto tem a ver com a crítica do lugar que eu reservo à política nesse debate. Penso que aquilo que escrevo é político, embora não seja sobre política. É político porque está atacando estruturas teóricas que são hoje hegemônicas nas ciências naturais e na psicologia, e em boa parte nas ciências sociais também, e que são respaldadas por corporações e pelo poder do Estado. Em muitos sentidos, considero esta postura repugnante do ponto de vista moral e ético. Ao atacar estes marcos teóricos, o ato em si de escrever contra eles é político, e talvez até mais político do que aqueles pesquisadores que escrevem sobre política. Se, por exemplo, colocássemos lado a lado dois estudos: o primeiro, um estudo antropológico das políticas da ciência contemporânea que pesquisasse, por exemplo, as razões pelas quais a psicologia evolutiva é tão poderosa e importante hoje; o segundo, que confronta a psicologia evolucionária, expõe seus princípios e mostra por que esses princípios são errados. Seriam dois tipos bem diferentes de estudo: o segundo não falaria nada sobre política, mas acho que seria mais político.

C.M. Como fazer pesquisa em sintonia com a ideia de fluxo em seus múltiplos movimentos? Não estaríamos fugindo de um procedimento heurístico básico em qualquer disciplina científica - separar artificialmente um conjunto de processos para compreendê-los em sua especificidade, colocando em "stand by" todos os outros, que ficam como pano de fundo? Em outras palavras, a obviação quer nos levar para fora da ciência encaminhando-nos para o campo das artes ou da poiesis?

T.I. Sim, acho que ela faz exatamente isso, que remete a um debate que venho desenvolvendo sobre a relação entre a antropologia e a etnografia. Acredito que a antropologia deveria ser uma investigação que olha para frente, uma investigação prospectiva e especulativa, na qual nós aprendemos dos outros, e usamos esse conhecimento para caminharmos juntos.

Há uma classe de pesquisa etnográfica retrospectiva, perfeitamente válida e correta, que coleta materiais através dos métodos usuais e depois escreve alguns comentários sobre o que a vida é, ou foi, para um tipo de gente, em um determinado momento. Esse tipo de escrita etnográfica é necessariamente retrospectiva, não quero dizer com isso que seja regressiva, mas ela olha para trás, para aquilo que aconteceu, aquilo que foi anotado em nosso caderno de campo, e depois analisado. Mas eu acho que a antropologia deve ser prospectiva, ela deve olhar para frente, para o mesmo tempo no qual estão as pessoas com as quais trabalhamos.

$\mathrm{Na}$ antropologia, deveríamos lidar com as pessoas que são nosso "objeto de estudo" da mesma forma como lidamos com colegas pesquisadores, 
ou com pessoas de outras disciplinas. Como estudantes, se nos encontramos com um acadêmico renomado, fazemos isso para aprender com essa pessoa, para ter alguns insights, para ter conversas e debates críticos; e o propósito disso não é escrever, pelo resto da vida, sobre o que esse acadêmico disse, ou escrever sua biografia, ou descrevê-lo, mas sim trazer o saber que se aprendeu com essa pessoa para qualquer problema ou questão que podemos vir a enfrentar futuramente. Não vejo por que deveria ser diferente no caso da antropologia. Nós trabalhamos com pessoas que deveriam ser convidadas para participar de uma grande conversa, e essa grande conversa é a respeito de como no mundo estão se moldando a humanidade e uma forma humana de vida que possam ser adequadas e possíveis no futuro.

Acho que, sem dúvida, os modelos que tivemos nos últimos cem ou duzentos anos nos falharam nesse sentido de forma significativa; precisamos encontrar formas alternativas de viver e decidir qual é a tarefa da humanidade, como vamos viver nesse mundo. Para isso precisamos de toda ajuda possível. Não que isso signifique que tenhamos que concordar com tudo o que as pessoas nos dizem, mas podemos aprender com elas. E a boa coisa da antropologia é que ela pode expandir de forma muito abrangente nossas formas e fontes de conhecimento. Os antropólogos ao redor do mundo conhecem muitas pessoas, e aprendem com elas. Nós podemos trazer todo esse conhecimento à grande conversa sobre como moldar uma humanidade para todos nós.

Acho que é disso que a antropologia deve tratar: de como criar uma forma de ser humano em um mundo para o qual nós estamos indo. Quando se confunde antropologia com etnografia, como sempre acontece, tendemos a desistir dessa esperança prospectiva e especulativa do que é ser humano, e nos concentramos no que um grupo de pessoas pensa e faz; ou corremos o risco de pensar que em algum lugar, de alguma forma, algum grupo indígena tem o segredo do futuro da humanidade, se é que se pode encontrá-lo - e isso é, evidentemente, errado, ou ao menos naïf.

O futuro é algo que temos que moldar para nós, não é algo que já está pronto nas mãos de algum grupo indígena, ou de alguma disciplina, ou de algum grupo acadêmico, temos que forjar isto juntos. Precisamos, pois, de toda ajuda possível nessa tarefa, e é esse que deveria ser o papel da antropologia. Preocupa-me ver o quanto esse foco na etnografia estreitou nossas ambições. Não estamos lá, os antropólogos, participando dos grandes debates a respeito de um futuro para os seres humanos na Terra.

Octavio Bonet. Do ponto de vista institucional, você acha que a perspectiva da obviação teria implicações para a construção de uma nova disciplina? Como foi talvez o caso da cibernética nos anos I940 e 1950, que propunha uma transversalidade dos campos. No artigo "From complementarity to obviation" você se refere à antropologia, à psicologia e à biologia, mas no prefácio do seu 
livro Being alive, você também inclui arte e arquitetura. Haveria uma continuidade entre a proposta da cibernética e a sua?

T.I. Esta é uma pergunta interessante. Eu não havia refletido sobre isso. O ponto óbvio de contato entre os dois é Bateson, que foi um autor central para o movimento cibernético naquela época, e eu diria que seu pensamento está no cerne daquilo que eu estou tentando fazer agora. Contudo, é importante notar as diferenças entre o contexto intelectual mais amplo dos anos I940 e I950 e o de hoje, o que nos faz perceber as coisas de forma bem diferente.

No fim das contas, a cibernética acabou levando à criação de mísseis guiados e de sistemas de armas. Bateson certamente nunca teria imaginado que isso poderia acontecer - mas aconteceu -, e não acho que nada do que eu estou propondo vai ajudar para o desenvolvimento de sistemas de mísseis guiados (espero que não!). Mas há algo em comum, sim.

Acredito que a cibernética foi a precursora daquilo que hoje se chama de uma abordagem relacional das coisas, que percebe o mundo em que vivemos não como sendo constituído de entidades particulares individuais, mas de movimento, relações e fluxos, que vê o mundo como fundamentalmente dinâmico em seu movimento, e as coisas que observamos nele como emergindo desse movimento. Isto é básico na abordagem que eu quero desenvolver quando associo antropologia, arte, arquitetura e arqueologia também.

Acho que este tipo de abordagem dinâmica, que fala das estruturas e de sua emergência nos fluxos de materiais, energias e informação, está também na base da cibernética. Então há, sim, uma relação aí, mas não conheço o suficiente da história da cibernética para responder apropriadamente à pergunta. De alguma maneira, parece que a cibernética foi cooptada pelas pessoas que moldam o sistema e se tornou, de fato, uma ramificação da engenharia. Quanto mais isso foi acontecendo, mais as pesquisas cibernéticas se fecharam sobre si mesmas e esse processo foi se tornando diferente daquilo que eu vejo, que é fundamentalmente aberto. Este é um aspecto crucial. Neste tipo de campo que eu quero criar não se investigam soluções finais, ou respostas técnicas para problemas, estamos procurando a forma sob a qual as coisas podem continuar, uma forma de falar sobre as coisas que seja sempre aberta, que compreenda a natureza do mundo, mundo este em formação contínua. Então não há respostas finais para isto porque as respostas são parte desse processo de formação.

Penso que isto vai além daquilo que a cibernética falava nos anos 1940 e I950, que era um tipo de pensamento que hoje se tornou quase dominante em algumas áreas da ecologia, por exemplo, ou da engenharia, das ciências químicas. Mas é uma questão interessante.

O.B. Em seu livro Being alive, você desenvolve a noção de uma malha [meshwork] onde se constrói o mundo como linhas emaranhadas de crescimento e 
movimento, e você nos vê como organismos nesse processo de habitar. A noção de um organismo em seu ambiente é aberta e plástica, de um modo que vai de encontro com a concepção de corpo que é hegemônica no Ocidente como produto de um processo de inversão e encapsulamento. Nesse sentido, penso no conceito de corpo e individuação no trabalho de Le Breton. Será que essas ideias do mundo como uma malha e das pessoas como organismos não nos levam a um humanismo para além da humanidade?

C.M. Complementando a pergunta de Octavio, você concordaria que o seu convite para fazer uma antropologia que retorna à vida poderia ser compreendido como uma forma de animismo reavaliada?

T.I. Acho que poderia, sim, ser vista como uma forma de animismo. Houve um retorno do interesse sobre o animismo na antropologia, sobretudo nos últimos dez anos, e pessoas como Eduardo Viveiros de Castro foram centrais para isso. Outros pesquisadores também retomaram essas ideias, e eu acho que esse é um desenvolvimento importante na antropologia.

Por cem anos, desde os trabalhos de Tylor, pensávamos e assumíamos que o animismo era uma forma primitiva de religião calcada na crença em seres espirituais e de que objetos inanimados têm alma e esse tipo de questão. E foi apenas recentemente que os antropólogos começaram a perceber que o animismo é, de fato, um tipo de ontologia, que é, logo, tão coerente quanto, digamos, as ontologias naturalistas ocidentais, sobre as quais a ciência se baseia. Ela não apenas é ontologicamente coerente, mas é também consistente com outros escritos filosóficos, especificamente aqueles que vêm das pesquisas da fenomenologia.

É possível ler a fenomenologia como uma forma de animismo. Aquilo que dizem os povos indígenas sobre a vida, o que as coisas são, como elas funcionam, não está muito distante daquilo que Merleau-Ponty e autores do tipo estariam dizendo sobre a vida. Então há mesmo uma convergência produtiva interessante entre estratos do pensamento europeu e aquele, não europeu, que circula em torno dessa ideia de animismo.

No que diz respeito à humanidade, talvez o aspecto mais importante dessa questão seja a ideia de que nossa humanidade não é algo dado, mas algo que deve ser continuamente trabalhado, que é um processo, uma tarefa. Eu acho que isso é realmente importante. Nesse sentido, é possível dizer, sim, que há uma humanidade além do humanismo, ou algo nesses termos. Isso significa que ser humano é uma realização, alguma coisa que tem que ser produzida continuamente, feita e trabalhada coletivamente.

Que tipo de seres nós somos? Este tipo de resposta não nos é dada. E de alguma forma a história é a nossa tentativa de responder a esta pergunta. E é preciso lidar com isso continuamente. Uma das implicações éticas ou morais disto é que se a vida humana é uma tarefa, se aquilo que nós estamos tentando fazer de nós mesmos é algo que deve ser resolvido con- 
tinuamente, então também temos responsabilidades por isso, responsabilidades históricas pelo tipo de seres que somos. Não é possível dizer simplesmente que, por conta da nossa natureza, ou porque nascemos em uma determinada sociedade, ou determinada cultura, tornamo-nos o tipo de seres que somos. Se estamos continuamente nos fazendo e refazendo, e se a história é esse processo, então temos uma responsabilidade sobre isso. É por isso que eu sempre volto a Marx no seu i 8 Brumário [0 I8 de Brumário de Luís Bonaparte], com sua famosa frase que diz que os homens fazem a sua história, não em circunstâncias escolhidas por eles próprios, mas nas circunstâncias que lhes foram dadas e transmitidas pelo passado. De alguma forma isso resume tudo, eu acho que ninguém resumiu esse ponto melhor do que ele. A humanidade e a história são, num certo sentido, a mesma coisa, e precisam ser resolvidas.

O.V. Falando sobre essa relação com algumas correntes do pensamento ocidental, como é que você vê a sua relação com o vitalismo do século XIX?

T.I. Eu gosto do vitalismo. Quando estava escrevendo um livro que ninguém lê, Evolution and social life [A evolução e a vida social] (I986), retomei as ideias de evolução criadora de Bergson, publicadas em I907.

A história é que eu estava na biblioteca da Universidade de Manchester procurando uma outra coisa e deparei com essa obra intitulada A evolução criadora. Naquela época eu estava começando a pensar naquilo que os biólogos querem dizer quando falam de processo evolutivo, da criatividade do processo evolutivo. Então eu peguei e li esse livro, que parecia não ser lido há muito e fazia espirrar pela poeira acumulada. E fiquei completamente tomado por ele. Pensei: eis aqui Bergson, sobre quem eu não sei nada, dizendo neste livro tudo que eu estava tentando dizer. E meu livro se tornou uma comparação entre Bergson e Darwin sobre a questão da evolução.

Ninguém leu esse trabalho porque meus colegas da antropologia social achavam que qualquer pessoa que escrevesse sobre evolução deveria ser um sociobiólogo; e, por outro lado, os biólogos achavam que as pessoas que mencionavam Bergson deviam estar completamente malucas. Então ninguém leu o livro. Mas eu fui muito influenciado por Bergson e tanto suas ideias se tornaram parte do meu pensamento que às vezes, hoje em dia, quase esqueço e tenho algumas ideias que não sei de onde vêm, e no fim das contas percebo que são de Bergson.

Lembro que fiquei muito entusiasmado com o que li. Participei de algumas oficinas com filósofos da Universidade de Manchester e dizia aos colegas o quanto estava interessado nos trabalhos de Bergson; as pessoas fechavam a cara e me diziam: "tudo bem para mim como antropólogo", mas tinham que se preocupar com suas carreiras e não deviam citar gente como Bergson. Já hoje ele está muito na moda. 
Mas acho que Bergson foi relegado a um segundo plano não pelo vitalismo em si, mas pela noção particular do élan vital, que está no cerne da questão. O que Bergson estava tentando dizer, creio eu, era que havia uma dinâmica generativa do próprio processo da vida. Ele dizia que era como se houvesse um espírito que estivesse na matéria e que passasse de uma geração para outra, era sua forma de falar do tema. Assim ele ficava imediatamente vulnerável a críticas das ciências naturais, que não consideram questões místicas ou entidades espirituais. Eles desprezavam o trabalho na sua totalidade, e foi um caso de se jogar fora o bebê junto com a água do banho.

A forma como Bergson expressava essa ideia de élan vital acabou sendo mal-vista. Isso derivava em que o vitalismo como um todo era rejeitado e com isso era também rejeitado o que acho que é realmente importante no vitalismo: a centralidade do processo da vida em si. Não que exista algum tipo de entidade mística, mas que o processo da vida vem antes, ou seja, precede ontologicamente as formas que a partir dele, depois, se constroem. Essa prioridade do processo ante a forma é crucial no vitalismo. E, neste sentido, o vitalismo é absolutamente válido como uma forma de abordar as coisas.

Mas tem havido um ressurgimento dessas ideias. Pessoas como Jane Bennett, em seus trabalhos recentes sobre matéria vibrante, também falam do vitalismo dos materiais e coisas do gênero. Estamos todos voltando a falar nisso.

C.M. Na conferência que você deu no Rio de Janeiro, você defendeu que artesãos, artistas, designers, todos são caçadores de sonhos; isto porque sua percepção seria equivalente à imaginação. Você concordará, contudo, que um caçador de sonhos ianomâmi é diferente de um caçador de sonhos escocês. Não seria uma contradição que o mesmo ato que diz que nós compartilhamos uma condição comum é também a prova de que estamos em modalidades diferentes de engajamento com o mundo?

T.I. Sim. Do modo como eu entendo a pergunta, ela tem a ver com a semelhança e a diferença. Se pensarmos na percepção e na imaginação das formas como eu estou sugerindo, como é que podemos lidar com a diferença, no caso entre um ianomâmi e um escocês? É uma pergunta difícil.

Acho que quero, de algum modo, ir além desse cálculo semelhança- diferença, ir além daquilo que os seres humanos têm em comum e de que maneira eles diferem uns dos outros. Ainda não tenho certeza sobre o que quero colocar no lugar disso. É o problema quando, em cursos introdutórios, explico aos meus alunos que querem saber sobre o sentido de termos como natureza e cultura, que esses são nomes para perguntas, e não suas respostas. Quando falamos em cultura, isto é o nome de uma pergunta, que é: "Por que os humanos são diferentes uns dos outros?" O que também quer dizer que "cultura" não pode ser a resposta a essa pergunta. Não podemos dizer que a cultura se deve à cultura, este seria um debate circular. Esta é minha crítica 
a muita da visão psicológica, bastante inepta, que fala que temos uma cultura que faz com que nos comportemos de uma forma ou de outra. É inteiramente circular.

A mesma coisa acontece com a natureza, a natureza é o nome de uma pergunta, que poderia apenas ser: “O que torna as pessoas elas mesmas?". E a resposta não pode ser que é uma diferença de natureza, o que seria, novamente, um argumento totalmente circular.

Como todo mundo, eu realmente quero fugir dessa dicotomia entre natureza e cultura, e fugindo dela estou também tentando refletir sobre a necessidade de ir além da polarização dessas duas perguntas: o que torna as pessoas iguais e o que as faz diferentes. Estou tentando me afastar dessa espécie de jogo de classificação.

Aqui estamos cinco pessoas numa sala. O que temos em comum, o que temos de diferente? Podemos falar dos nossos olhos, narizes, que estamos vestidos de uma forma ou de outra, então dizemos que temos algumas coisas em comum, e outras que não partilhamos, mas isto já é assumir que temos uma série de entidades essencialmente comparáveis. Então diríamos: temos um ianomâmi aqui e um escocês ali, mas ambos são seres humanos, ambos têm olhos, nariz e boca, logo têm algo em comum, e alguma diferença é colocada em cima disso.

Se pensarmos, porém, nas vidas humanas como movimentos, de alguma maneira o exercício comparativo não funciona do mesmo modo. Eu acredito, sim, que a antropologia é uma disciplina comparativa, não porque estamos comparando este grupo de pessoas com aquele outro grupo de pessoas, mas porque, quaisquer que sejam os grupos com os quais trabalhamos, sempre estamos nos perguntando por que é que eles estão fazendo as coisas desse modo específico, e não de outro. Acho que isso é fundamental para a atitude antropológica. Quando estamos olhando para um certo modo de vida, as pessoas tomam uma certa direção, mas sempre temos na cabeça o reconhecimento de que a direção que elas tomaram não é a única direção possível e que há uma multiplicidade de outras opções possíveis, que são igualmente válidas, coerentes ou consistentes.

Podemos dizer que todo mundo está tentando encontrar uma forma de atravessar barreiras - o ianomâmi por um caminho específico, essa pessoa hipotética escocesa por um caminho diferente -, mas seria difícil comparar duas pessoas como se fossem entidades, assim como também seria difícil fazê-lo com duas trilhas em uma paisagem. Ninguém se pergunta no que elas são parecidas ou no que elas diferem, esse tipo de pergunta não faz tanto sentido. As pessoas dizem simplesmente que elas não vão na mesma direção, mas que ambas as direções são trilhas. Podemos dizer que esse ianomâmi e esse escocês estão caminhando em direções diferentes, mas isso não os torna entidades diferentes, ou seja, precisamos de uma linguagem de compara- 
ção que nos permita falar de caminhos e movimentos, e de caminhos como movimento, ou seja, como linhas, mais do que como entidades. Acho que ainda não encontrei essa linguagem, mas a ideia é essa.

C.M. Mas você estaria dizendo, com isso, que não há comensurabilidades?

T.I. Não. Evidentemente, há semelhanças, familiaridades e há, sim, comensurabilidades, mas precisamos encontrar uma forma de falar sobre a comensurabilidade - que não nos obrigue a assumir um nível subjacente que estabeleça o que todos os seres humanos têm em comum - como um fundamento a partir do qual fazer as medidas.

Se dizemos que dois seres humanos são comensuráveis, poderiam dizer que, de alguma forma, estamos comparando semelhança com semelhança. Se as coisas são comensuráveis, ou se para torná-las comensuráveis é preciso comparar semelhança com semelhança - e quando dizemos isto imediatamente assumimos uma semelhança fundamental -, isto não pode estar certo. É preciso encontrar outra linguagem para que a comparação e a comensurabilidade ainda façam sentido, sem termos que assumir que dependem de um tipo de semelhança fundamental a partir da qual a diferença é sobreposta.

Acho que houve muitos intentos antropológicos para resolver isso, o perspectivismo é um, e há outros, mas acho que não encontramos (ao menos eu não encontrei) uma solução para isso. Não sei que linguagens alternativas poderia haver e o que nós queremos dizer com a comensurabilidade de todos os seres, não apenas os humanos. Como podemos falar sobre isto sem recorrer a um nível subjacente de semelhança universal? Ainda não consegui resolver esta questão, acho que é um problema importante para a antropologia.

Rosane Prado. Quais são os autores que mais influenciaram o seu trabalho e quais são aqueles que você vê como mais próximos à sua produção? Como você percebe as divergências entre o seu trabalho e o de Bruno Latour?

T.I. Grande parte do trabalho que me influenciou não necessariamente é de antropólogos. Há pessoas que me inspiraram em diferentes momentos, que foram importantes no passado, e que já não são tão importantes agora, mas eu não estaria aqui hoje se eles não tivessem sido importantes antes. É interessante pensar sobre isso.

Um dos primeiros livros que li quando decidi mudar das ciências naturais para a antropologia, quando eu era estudante em Cambridge, foi um pequeno livro de Marshall Sahlins \& Elman R. Service chamado Evolution and culture [Evolução e cultura] (I960). É um livro pequeno que, por sua vez, foi muito influenciado pelo trabalho de Leslie White, no qual Sahlins \& Service dizem que a cultura avança na medida em que é capaz de armazenar e utilizar a energia do ambiente. Então fui conversar com meu orientador, disse-lhe que estive lendo esse livro, que o tinha achado muito inspirador, e ele me disse: 
"Nunca, jamais, volte a ler nada como isso!". Tratava-se de uma tentativa de casar os sistemas da biologia e da antropologia de forma holística para tentar compreender a evolução de uma maneira ampla, algo que eu sempre tentei fazer: juntar aspectos sociais e biológicos de forma holística para ajudar a entender os processos evolutivos de forma abrangente. Por isto foi um livro importante desde o começo.

Mais tarde, ainda na graduação, li o trabalho de Irving Hallowell, que era pouco valorizado na época, mas já na metade dos anos 1950 ele estava publicando artigos juntando processos psicológicos, biológicos e sociais de formas bastante visionárias. Há problemas no trabalho de Hallowell. Ele es tava interessado nos testes de manchas de tintas, e coisas desse tipo, aplicados com os índios Ojibwa, mas eu acho que, entre os vários antropólogos, o trabalho de Hallowell foi o mais importante na minha formação. Ele trabalhou com os Ojibwa do Norte do Canadá - eram caçadores e coletores - dos anos I930 aos anos 1950. O último artigo foi publicado nos anos I960, "Ojibwa ontology, behavior and world view" ["Ontologia, comportamento e visão de mundo dos Ojibwa"]. Este trabalho, para mim e para muitas pessoas que trabalharam no Polo Norte e com pesquisas no Ártico, é como uma Estrela do Norte. É aquele tipo de artigo em torno do qual tudo gira e ao qual se fica voltando. Nos anos 1960 ele já estava mesmo introduzindo questões de perspectivismo, da pessoalidade não humana, da constituição relacional do ser, e da ontologia animista, associando tudo isto com formas não cognitivas de psicologia, já antecipando o ponto de Bateson, ou seja, que a mente não termina no nível da pele. Estava tudo lá e por isso Hallowell foi uma influência realmente importante para mim. Bateson é outra.

Quando penso em processos culturais e na aprendizagem, uma pessoa importante foi Jean Lave, pesquisadora que fez seu trabalho de campo no Brasil e que depois passou dois períodos conosco em Manchester. Uma pessoa fantástica, que me ajudou muito, de diversas maneiras, que foi uma inspiração intelectual, sobretudo no que diz respeito à aprendizagem. Autores como o psicólogo russo Vigotsky estavam muito presentes em suas reflexões, e foram importantes também para mim.

Marshall Sahlins foi mais uma influência, ainda que de forma contrária, assim como Clifford Geertz. Quando cheguei ao departamento em Manchester, Geertz visitou o departamento e todos reverenciavam esse grande homem. Eu o achava intolerável e arrogante, não gostava de sua escrita, que me parecia confusa. E ainda penso isto sobre ele. O que me lembra que outra influência importante foi Alfred Kroeber, hoje muito esquecido, mas que, já nos anos 1920 ou I930, estava escrevendo coisas realmente interessantes sobre biologia, ecologia, e sobre como isso se conecta com a cultura. Kroeber era um autor de muita verborragia, que usava mil palavras para escrever coisas que se podem escrever em dez, então seus livros eram gigantescos. A razão pela qual ninguém 
lê Kroeber é por causa de Geertz, que, por sua vez, retomou o que ele tinha deixado e continuou a escrever desse jeito um pouco à deriva.

Mas aqui é Kroeber que está sendo lembrado, foi um autor importante e uma influência para mim.

Sahlins foi uma influência importante porque eu sempre estive tentando me contrapor a ele, de formas evidentemente muito amigáveis.

E, por fim, há as pessoas já fora da antropologia, como a Susan Oyama, que é filósofa da biologia, e seus trabalhos sobre Teoria do Desenvolvimento são absolutamente cruciais; James Gibson, fundador da psicologia ecológica; Bergson também, absolutamente crucial, sobre quem já falamos; e, subsequentemente, os incompreensíveis filósofos franceses como Merleau-Ponty, Deleuze e Guattari - só agora eu começo a entender um pouco o que eles querem dizer, apenas agora consigo decifrá-los, acho que eles não se expressam muito bem.

Essas pessoas foram as que mais me influenciaram. Quanto às pessoas que fazem trabalhos próximos ao meu, é uma pergunta realmente difícil de responder. Acho que muitas estão fazendo ou pensando coisas semelhantes ao que eu digo, tanto no âmbito da antropologia como fora. Há pessoas com quem eu discuto regularmente e que estão próximas, porque foram meus alunos, ou porque são pessoas com quem trabalho: como Gisli Palsson, Rane Willerslev, Stephanie Bunn, que foi minha aluna muitos anos atrás, e que não é conhecida internacionalmente, mas é uma excelente artesã, além de antropóloga. Aprendi muitíssimo com os trabalhos dela e trabalhando com ela. É difícil listar as pessoas desse jeito. É difícil responder a essa pergunta de modo preciso.

Sobre o Bruno Latour, eu acho que é difícil lidar com ele. Diria que um terço de sua obra diz aos antropólogos para fazerem o que sempre fizeram, ou seja, seguir seu faro. Qualquer antropólogo que fez trabalho de campo sabe que o que fazemos é isto: colocar o nariz no chão e seguir pistas, uma coisa leva à outra, e vemos então que tudo o que acontece é parte dessa rede de coisas em que uma afeta a outra e tudo está interligado. Então Latour simplesmente nos diz para fazer o que sempre fizemos. Isso é um terço de seu trabalho; um outro terço é um ataque às grandes teorias sociais e às questões sociológicas que não nos interessavam muito de todo modo; e o último terço são disparates dele. Neste sentido, acho que nunca tirei muito proveito dos trabalhos dele, mas um dos principais problemas que tenho ao lidar com Latour (talvez outras pessoas tenham esse problema comigo) é a questão, simplesmente, da sua inconsistência. Ele diz uma coisa em uma página, e depois diz uma coisa completamente diferente em outra, e isto não parece ser um problema para ele, mas torna muito difícil a possibilidade de se criticar o que ele diz. A última vez que estive face a face com Latour discutimos sobre o meu livro Lines e o argumento dele era basicamente o seguinte: ele dizia que poderíamos descrever uma interação de dois "actantes", A e B, através de uma 
linha que se pode desenhar entre eles. Mas poderíamos também, se quiséssemos, pensar em A como uma linha e em B como outra linha, e poderíamos descrever sua interação como um ponto da interação das duas. No primeiro caso, A e B são pontos e a interação é a linha, e neste último caso, A e B são linhas e a interação é um ponto. No argumento de Latour, ele diz que são equivalências matemáticas ou topológicas. Então ele me perguntava: "Por que você faz toda essa discussão sobre as linhas? Você pode desenhar de uma forma ou de outra. É possível falar de uma rede ou de uma malha, isso não faz grande diferença, são apenas formas matemáticas diferentes de explicar exatamente a mesma coisa". E eu lhe dizia então que isso funcionaria se falássemos de forma abstrata e matemática, mas se A e B são seres vivos, e se descrevemos a vida de A como uma linha e a vida de B como outra linha, não estamos descrevendo A e B como pontos. Isso é tudo, menos equivalente, porque, ao se converter a linha em ponto, tem-se uma inversão, que extingue o movimento e torna A e B objetos, e sua relação torna-se uma relação abstrata entre dois objetos; ou seja, em vez de dois caminhos que estão se movendo juntos e em mútua correspondência, ele coloca um ponto aqui e outro lá, e eu acho que isso é uma redução fundamental; este é o problema que tenho com sua noção de ator-rede [actor-network]. Mesmo em seus trabalhos sobre ecologia política, em que ele tenta dizer que não precisamos ter um conjunto de coisas que pertencem à natureza e outro à sociedade, e, sim, muitas coisas que estão conversando umas com as outras. Não há nada em suas análises sobre materiais ou energia e isso é o que faz com que a ecologia política dele, a meu ver, seja fundamentalmente antiecológica. Não há nada sobre fluxos de materiais e de energia, que são, de fato, essenciais para a vida. Então é como se faltasse a própria vida na ecologia de Latour.

Essa é a dificuldade real que tenho em relação ao trabalho dele e é por isto que eu gostaria de manter a diferença que estabeleci entre malha e rede, porque acho que a malha, sim, diz respeito ao movimento, ao fluxo e aos fluxos de materiais da vida.

Ultimamente, venho desenvolvendo um novo conceito, a que dei o nome de "correspondência", ou "co-respondência", em que há caminhos diferentes, linhas diferentes, que respondem umas às outras do mesmo modo como fazem as linhas musicais no contraponto; de alguma forma isto mostra o que estou tentando dizer. Em vez de uma rede com atores que interagem, eu proponho uma malha de linhas que se correspondem e movem. Daí as diferenças que tenho com o trabalho de Latour, até onde posso ver. Mas é um assunto difícil de resumir.

C.M. Nos últimos anos você organizou várias coletâneas com seus alunos e outros pesquisadores, como o Creativity and cultural improvisation [Criatividade e improvisação cultural], Ways of walking [Formas de caminhar] 
e Redrawing anthropology [Redesenhando a antropologia]. Como você descreveria esse tipo de parceria? Você trabalha no sentido de fazer antropologia de uma nova maneira?

T.I. Eu espero que sim. Os livros que você mencionou, Ways of walking - exceto o Criatividade e improvisação cultural, que é resultado de uma conferência da Associação de Antropologia Britânica -, assim como os mais recentes Imagining landscapes e Making and growing, são todos parte de uma série intitulada Estudos Antropológicos sobre Criatividade e Percepção, publicada pela Ashgate. A ideia da série era funcionar como uma espécie de vitrine para o trabalho que estamos desenvolvendo em Aberdeen com pessoas que fazem parte de nossa rede mais ampla. São livros bastante especializados, caros, e não imagino que muitas pessoas os comprem, mas nós temos esta série.

Acho que estamos desenvolvendo em Aberdeen uma forma bastante distinta de fazer antropologia. Algumas de nossas características são a ênfase que damos ao movimento, ao artesanato, ao fazer as coisas com materiais, ao desenho. É muito interessante pensar nos potenciais do desenho como método antropológico. Nós estamos explorando todas essas coisas de forma bastante coletiva, tenho feito isso com colegas e alunos de pesquisa. A proposta despertou muito interesse. Quando as pessoas vão a Aberdeen, dizem que temos uma forma bastante peculiar de fazer antropologia, que é bastante diferente daquela desenvolvida pela University College, de Londres. Eles também têm uma forma distinta e reconhecida de fazer antropologia por lá, nos seus estudos de cultura material, e nós temos também nossas particularidades em Aberdeen.

No passado as pessoas falavam de escolas de antropologia, havia a escola de Manchester, a escola de Cambridge, cada uma com suas abordagens específicas. Hoje, no Reino Unido, já não há exatamente escolas desse modo, não há departamentos que estejam forjando suas abordagens distintivas a respeito ao que querem fazer, para onde querem levar a antropologia. Talvez isso seja até um pouco pretensioso, mas eu espero que no futuro alguns historiadores falem da escola de antropologia de Aberdeen, o quão diferente era, e como ela foi capaz de levar a antropologia para uma direção específica, que é reconhecida não como tendo sido a única, mas por ter sido valiosa. Seria muito bom se a história pudesse olhar para aquilo que nós fizemos.

Mas não sou só eu, há um grupo de pesquisadores. Uma das coisas mais interessantes é que isso realmente tem chamado a atenção de pessoas que não necessariamente são antropólogas, mas que se interessam pela disciplina, pela maneira como nós a tratamos, como, por exemplo, artistas e arquitetos. As pessoas nos visitam, querem saber o que estamos fazendo, ficam circulando por lá. 
C.M. Em sua reflexão antropológica, você sempre deu muita atenção à formação do skill. A sua paixão pelo violoncelo tem alguma participação nesta convicção, da importância do skill? Na sua produção individual, você desenvolveu algum tipo de correspondência, por exemplo, buscar o arco do violoncelo para, digamos assim, abrir o caminho de uma reflexão intelectual que empacou e vice-versa?

T.I. Como o fato de tocar violoncelo se relaciona com a minha antropologia? É verdade que o fato de tocar violoncelo influenciou a forma como eu penso e trabalho como antropólogo, e eu devo muito a isso. Em parte porque não sou muito bom fazendo qualquer outra atividade que tenha a ver com artesanato, e eu acho que tocar um instrumento é uma espécie de artesanato e me dá alguma autoridade para falar sobre o tema. Então, muitas das coisas que se podem dizer sobre tocar violoncelo podem servir para outras atividades artesanais. Richard Sennet, por exemplo, toca violoncelo também e, embora ele não tenha dito isso diretamente, acho que foi essencial para ele quando es tava escrevendo sobre artesãos, e foi este o caso para mim também. Quando estou pensando sobre artesanato e sobre habilidades, tocar violoncelo me fornece um bom modelo para pensar, é o que eu faço melhor fora do meu trabalho propriamente de escrita.

Acho que outra coisa sobre a qual tocar violoncelo teve influência foi a minha maneira de escrever. Estou bastante cansado desse tipo acadêmico contemporâneo de escrita, esse que aparece em artigos e revistas acadêmicas, eu acho muito disso bastante desprovido de qualquer tipo de poesia, cheio de referências... reverenciando uma ou outra literatura, e as bibliografias vão se tornando cada vez mais extensas, enquanto o poder das palavras parece que vai se perdendo. Quero voltar a um tipo de escrita na qual sentimos qualquer coisa de certo, e eu faço isto ao ler em voz alta o que escrevo, para ver se soa bem, se o ritmo é bom, se tem boas inflexões melódicas; e se acho que está errado, volto ao texto e procuro outras palavras.

É engraçado como as coisas são. Eu não sou um poeta, e eu leio pouca poesia, mas as pessoas insistem em me dizer que o que eu escrevo é, de certa forma, muito poético. Só posso pensar, então, que isso se dá porque a grande maioria das pesquisas e da escrita acadêmica se tornou apoética. Não que o que eu faça seja poético, mas o que se faz na academia está tão distante da poesia da linguagem que as pessoas percebem esse contraste.

Acho que tocar violoncelo leva a uma forma intuitiva de apreciação rítmica e melódica da palavra. Isso quer dizer que não posso escrever sem sentir isso. Então eu me forço a escrever de uma forma que possa capturar esses aspectos e sentimentos melódicos e rítmicos. Também por isso o violoncelo tem sido importante. 
C.M. Em alguns de seus escritos você divide com o leitor algo da sua relação com seu pai, ou sobre seus anos de juventude. Como a sua vida com a Anna, sua mulher, se relaciona com seu trabalho?

T.I. Ela sempre reclama porque fica de fora, ela diz, por exemplo, que no Prefácio de Being alive eu falo da minha relação com o violoncelo, mas não faço os agradecimentos à minha relação com ela. "Quem é mais importante, eu ou o violoncelo?", diz ela.

Anna é uma crítica ferrenha das coisas que escrevo, o que quer dizer que para mim é realmente muito importante quando ela diz que eu escrevi alguma coisa que tem uma sonoridade boa. Acho que o que é fundamental mesmo é que Anna não é uma antropóloga. Eu não poderia me casar com uma pessoa que fosse antropóloga, acho que seria uma relação muito competitiva. Mas Anna sempre mantém meus pés no chão, e me lembra de que há outras coisas na vida além da teoria.

Ela sempre reclama e me diz: "Você escreve tudo isso, mas onde estão as pessoas?", e ela tem razão. Ela sempre me lembra da importância de focar numa relação mais concreta; e sem esse apoio eu certamente não seria capaz de escrever aquilo que escrevo.

É uma questão muito interessante. Nós, às vezes, discutimos a respeito da importância da família e da mulher no bem-estar geral de uma pessoa, na sua estabilidade emocional, sua capacidade de trabalhar, e sem isso eu não teria a capacidade de trabalhar que tenho. As relações afetivas são fundamentais, mas deveríamos ou não deixar tudo isso entrar naquilo que escrevemos?

Eu estava lendo um livro do poeta escocês Andrew Greig, no qual ele fala sobre sua vida a cada página, os altos e baixos, e me pergunto: "Por que será que esses autores querem mostrar a vida da família, para que todo mundo leia, para que todo mundo conheça, por que eles fazem isso?". O que a minha mulher me diz é que eu nunca falo que tenho família, que nunca faço referência a isso, e eu lhe digo que essa é a diferença entre ser um poeta, ou um romancista, e fazer trabalho acadêmico. E eu não sou um romancista, eu sou um acadêmico. Não tenho certeza de que deva haver esse tipo de informação no trabalho acadêmico, talvez devamos deixar este tipo de coisa transparecer mais em nossos trabalhos, não sei... Particularmente, eu acho que há coisas que são muito íntimas, acho que as coisas pessoais devem continuar pessoais, não devem ser expostas a todo mundo. O que não quer dizer que elas não sejam importantes, elas são de fato muito importantes, e eu não seria capaz de trabalhar sem elas.

O.V. Estou lendo um livro de um pesquisador indiano, Ashis Nandy. Muito interessante. Ele dedica o livro a sua familia e diz "sem eles este livro poderia ter sido finalizado antes, mas sem eles não seria o mesmo livro".

T.I. Penso que deveriam fazer essa pergunta à Anna. 
Anna Ingold. Na maior parte das vezes me sinto como uma mulher invisível. O Tim viaja muito pelo mundo, mas agora que nossos filhos já são adultos e que temos netos, estamos voltando a nos encontrar. Nos conhecemos faz 44 anos, em uma pequena cidade do interior da Finlândia. Nos correspondíamos por carta, como era usual naqueles dias. O telefone era muito caro. Posso dizer que morar com ele tem sido uma interessante linha de vida! Tim fala muito do pai, mas sua mãe foi quem o introduziu à música.

T.I. Meu pai era um micologista. Ele nunca conseguiu entender o que era essa tal de antropologia. Ele leu o meu livro Lines e me disse "Que raios é isto?!". Ele nunca conseguiu entendê-lo. E ainda assim eu penso que muito do que ele fez e da maneira como fez, de alguma forma não consciente ou não intencional, acabou me influenciando bastante.

Sempre penso, por exemplo, que, na botânica, a micologia está muito próxima da antropologia. Se você fosse um antropólogo e um botânico, você seria um micologista, porque os fungos não se comportam segundo os standars da biologia; eles são estranhos. E os micologistas são, para as ciências biológicas, o que os antropólogos são para as ciências sociais, é quase exatamente isso. São pessoas estranhas, que não se encaixam.

Meu pai se dedicava ao trabalho de campo e pesquisava organismos em seus contextos particulares e esse tipo de coisa foi muito importante para mim. Também a forma como ele fazia ciência na nossa mesa de jantar, ele olhava no microscópio para os esporos dos fungos e desenhava belíssimos diagramas a tinta indiana. Ele via os fungos como obras de arte e eram, sem dúvida, obras de arte. De algum modo, todas essas coisas se juntam.

R.P. Quero fazer uma pergunta sobre os cursos introdutórios de antropologia na graduação. Como professores, sempre encantamos os alunos com o tema central da cultura, damos-lhes exemplos, contamos-lhes histórias, como a que conto aos meus alunos, de um amigo sueco que eu tenho que, olhando para uma fotografia tirada num parque do Rio de Janeiro, ficou muito impressionado com umas flores brancas, que ele via em primeiro plano. Ele disse que nunca tinha visto um gramado com flores brancas como essas. Na verdade, não eram flores, era lixo. Esse amigo sueco via flores ali, onde nós víamos lixo. Enfim, histórias como esta apontam para valores diferentes, para formas de construção de sentido, e para a cultura em última instância. Como, na perspectiva que você propõe, poderíamos minimizar o peso dessa forte separação - que você precisamente critica - entre natureza e cultura, como podemos repensar isso, como ensinar antropologia desta sua perspectiva nos primeiros cursos da graduação?

T.I. Em relação a essa história que você contou eu diria que esse seu amigo sueco estava sintonizado com experiências anteriores para responder a certas coisas no ambiente, para notar certos detalhes, e de uma forma especí- 
fica. Imaginemos um exemplo parecido com este: duas pessoas, uma sueca e uma brasileira, caminham juntas pela cidade, e o que percebemos é que uma vê certas coisas que a outra não vê, e vice-versa. A questão é, então, o modo como entender o fato de que eles parecem ver um mesmo ambiente de formas distintas.

A resposta que a antropologia cognitiva tradicionalmente dá a essa questão é que dentro da cabeça de uma pessoa há um modelo cultural que foi recebido e que é usado para organizar os dados da experiência sensória. E na cabeça da outra pessoa, a mesma coisa, outro molde. Duas pessoas percebem as coisas de formas diferentes no ambiente porque, por mais que ambas recebam os mesmos estímulos sensórios, esses estímulos são organizados e categorizados em função de modelos culturais e de representação diferentes. Esse seria o argumento, ou a resposta clássica. Estamos todos numa mesma natureza, mas temos predisposições culturais distintas, e por isso percebemos coisas distintas.

Mas eu diria, contrariamente a isso, que elas veem coisas diferentes não porque estão construindo os mesmos dados sensíveis de formas diferentes, mas porque estão atendendo a diferentes aspectos daquilo que está no mundo, estão notando coisas diferentes. Então, se formos para a floresta com um caçador indígena, ele vai perceber pegadas de animais que você não notaria por falta de experiência, porque você não tem essas mesmas habilidades, ou porque você não está afinado, sintonizado para perceber esse tipo de coisa no ambiente. Assim, o que nós pensamos corriqueiramente como diferenças culturais são, de fato, diferenças de habilidades, de percepção, de ação, coisas que se desenvolvem em um corpo que cresce, através da nossa experiência de crescimento em um determinado ambiente.

A questão que coloco em The perception of the environment, que publiquei em 20II, é como podemos substituir a ideia de diferenças culturais por uma ideia de diferença de habilidades, de propriedades que se desenvolveram em determinados organismos. Seria isso que eu diria no meu curso introdutório de antropologia.

Esta é, sem dúvida, a questão fundamental da antropologia: por que duas pessoas com trajetórias diferentes, postas no mesmo lugar, percebem as coisas diferentemente, por que há tantas diferenças na percepção delas? Temos que pensar em algumas respostas para isso. Mas uma que apenas diz que "as pessoas percebem diferentemente coisas diferentes porque as pessoas são diferentes" não parece nos levar a lugar nenhum. Então, voltamos àquela questão de que cultura talvez seja o nome de uma pergunta, e não a resposta. 
Clara Mafra era doutora em Antropologia Social pelo Programa de Pós-Graduação em Antropologia Social no Museu Nacional da Universidade Federal do Rio de Janeiro (PPGAS-UFRJ) e professora associada da Universidade do Estado do Rio de Janeiro, no Programa de Pós-Graduação em Ciências Sociais (PPCIS). Publicou e organizou o livro Religiões e cidades - Rio de Janeiro e São Paulo (2009); Na posse da palaura - religião, conversão e liberdade pessoal em dois contextos nacionais (2002); e Os evangélicos (200I).

Octavio Bonet é doutor em Antropologia Social pelo Programa de Pós-Graduação em Antropologia Social no Museu Nacional da Universidade Federal do Rio de Janeiro (PPGAS-UFRJ) e professor adjunto do Departamento de Antropologia Cultural do Instituto de Filosofia e Ciências Sociais da UFRJ (IFCS-UFRJ) e do Programa de Pós-Graduação em Sociologia e Antropologia da UFRJ. Publicou Saber e sentir. Uma etnografia da aprendizagem da biomedicina (2004); e Os médicos da pessoa. Um olhar antropológico sobre a medicina de família no Brasil e na Argentina (2014).

Otávio Velho é doutor em Sociologia pela Universidade de Manchester (Grã-Bretanha) e professor emérito do Programa de Pós-Graduação em Antropologia Social do Museu Nacional da Universidade Federal do Rio de Janeiro (PPGAS-UFRJ). Publicou, entre outros livros, Mais realistas do que o rei: ocidentalismo, religião e modernidades alternativas (2007); Circuitos infinitos. Comparações e religiões no Brasil, Argentina, Portugal, França e Grã-Bretanha (2003); e Besta-Fera: recriação do mundo (I995).

Rosane Manhães Prado é doutora em Antropologia Social pelo Programa de Pós-Graduação em Antropologia Social do Museu Nacional da Universidade Federal do Rio de Janeiro (PPGAS-UFRJ) e professora associada da Universidade do Estado do Rio de Janeiro, Programa de Pós-Graduação em Ciências Sociais (PPCIS) e do Programa de Doutorado em Meio Ambiente (PPGMA). Organizou Itha Grande: do sambaqui ao turismo (2006); e A ambientalização dos conflitos sociais. Participação e controle público da poluição industrial (2004) 


\section{A ANTROPOLOGIA COMO PARTICIPANTE DE UMA GRANDE CONVERSA PARA MOLDAR O MUNDO. ENTREVISTA COM TIM INGOLD}

Resumo A entrevista enfatiza a perspectiva antropológica do Tim Ingold e seu modo particular de entender as relações ecológicas entre os organismos e o entorno. Para desvendar esta perspectiva o diálogo segue um percurso pelos anos de formação e pelas influencias teóricas do entrevistado, alem das relações com alguns pensadores das ciências humanas no contexto atual de produção do conhecimento.

\section{ANTHROPOLOGY'S PARTICIPATION IN A GREAT CONVERSATION TO SHAPE THE WORLD. INTERVIEW WITH TIM INGOLD}

Abstract

The interview focuses on the anthropological perspective of Tim Ingold, his particular way of understanding ecological relationships between organism and environment. To unravel the author's theoretical perspective, the dialogue follows through his formative years and theoretical influences, as well as the relationships established with other theories in the context of contem-
Palavras-chave Antropologia; Obviação; Criatividade; Ambiente; Vida.

Keywords Anthropology; Obviation; Creativity; Ambient; Life. 